Research

Human and Medical Genetics

\title{
Birth defects in Brazil: Outcomes of a population-based study
}

\author{
Camila Ive Ferreira Oliveira-Brancati ${ }^{1}$ iD, Valéria Cristina Carvalho Ferrarese ${ }^{1}$, Antonio Richieri Costa $^{2}$ and \\ Agnes Cristina Fett-Conte ${ }^{1}$ \\ ${ }^{1}$ Faculdade de Medicina de São José do Rio Preto (FAMERP/FUNFARME), São José do Rio Preto, SP, \\ Brazil. \\ ${ }^{2}$ Universidade de São Paulo (USP), Hospital de Reabilitação de Anomalias Craniofaciais, Bauru, SP, Brazil.
}

\begin{abstract}
Birth defects (BDs) are functional and structural alterations in embryonic or fetal development. With an incidence of approximately 3-5\%, BDs are a leading cause of infant mortality and lifelong disability. A population-based prospective case-control study was conducted for one year with 5204 infants, between March $1^{\text {st }}, 2011$ and February $29^{\text {th }}$, 2012 in the city of São José do Rio Preto, State of São Paulo, Brazil. The incidence of BDs was 3.2\% [95\% confidence interval $(95 \% \mathrm{Cl}): 2.8-3.8 \%]$. The most common congenital anomalies were heart diseases in isolation (11.2\%; 95\%Cl: $7.3-16.9 \%)$ followed by Down syndrome $(9.5 \% ; 95 \% \mathrm{Cl}: 5.9-14.8 \%)$, neural tube defects $(8.9 \%$; $95 \% \mathrm{Cl}$ : 5.4-14.1), urinary tract anomalies (7.7\%; 95\%Cl: 4.4-12.7\%), and polydactyly (7.0\%; 95\%Cl: 4.0-12.0\%). The majority of mothers with Down syndrome babies had advanced age. Family members with the same BD, maternal alcohol consumption, gestational diabetes, and previous miscarriages were the most frequent risk factors. The results were similar to published data from other countries except for the incidence of Down syndrome, which was twice as high as reported by other authors and is probably due to the high sociocultural level of the region where the current study was performed, leading to pregnancies at older maternal age.
\end{abstract}

Keywords: Malformation, congenital anomaly, fetal development, genetic counseling, public health.

Received: June 27, 2018; Accepted: February 2, 2019.

\section{Introduction}

Birth defects (BDs) are functional and structural alterations in embryonic or fetal development resulting from genetic, environmental, or unknown causes. BDs have a significant impact on the health and development of a child. They contribute to $50 \%$ of neonatal deaths, besides being a leading cause of infant mortality and lifelong disabilities (Gill et al., 2012; Arioglu Aydin et al., 2015). About eight million babies worldwide are born each year with significant BDs (Reece, 2012); the overall incidence is approximately 3-5\% (Oliveira et al., 2011; Gill et al., 2012). Although there are well-established risk factors, the causes of most BDs remain unknown (Miller et al., 2011; Kong et al., 2012; Wiener-Megnazi et al., 2012; Ooki, 2013).

While there are many published studies about BDs, few have been performed in underdeveloped and developing countries, with the majority being hospital-based and not population-based studies (Groisman et al., 2013). This article describes data on the incidence and risk factors of BDs obtained in a population-based study performed over one year involving 5204 Brazilian infants.

Send correspondence to Camila Ive Ferreira Oliveira-Brancati. Faculdade de Medicina de São José do Rio Preto (FAMERP/FUNFARME), Av. Brigadeiro Faria Lima, 5544, 15090-000, São José do Rio Preto, SP, Brasil. E-mail: camilaiveoliveira@ hotmail.com.

\section{Subjects and Methods}

This study was approved by the Research Ethics Committee of the Medical School of Sao Jose do Rio Preto (FAMERP \# 5838). The parents of all subjects were informed about the nature of the study and signed informed consent forms.

This population-based, prospective, case-control study collected data on all infants born in the city of São José do Rio Preto over one year, between March 1, 2011 and February 29, 2012. Located in the northwestern region of the state of São Paulo, Brazil, the city has a population of 408,258 and, according to the Instituto Brasileiro de Geografia e Estatística, it is the second most developed city in Brazil (IBGE, 2016).

The investigation was performed by a multidisciplinary team involving several kinds of health professionals, in particular neonatologists and geneticists, in all six hospitals of the city. In order to verify the populational character of the study, a partnership with the Health Department of São José do Rio Preto was made. Thus, births of children with BDs carried out in municipalities other than that of the mothers residing in the city could also be considered resident and characterized. However, during the study period, there was no birth of BD babies in a locality other than São José do Rio Preto, according to the official re- 
cords. In addition, babies born in the city, whose families resided in other municipalities were excluded.

During the study period, 5204 children were born and all were investigated for the presence of major and minor defects. The data of children with BDs (BD Group) were compared with data of healthy infants matched for gender and born in the same hospital immediately after each study case (Control Group). This Group was used to compare maternal and paternal data and obstetric and perinatal variables. Deaths were considered stillbirths when they occurred after 20 weeks of gestation (O'Neill et al., 2011). All cases of BDs were analyzed following the classification of Garne et al. (2011).

Trained researchers collected the data by face-to-face interviews with the parents and from medical records. Variables included sociodemographic data, obstetric history, family antecedents, previous pregnancies, periconceptional folate supplementation, gestational exposure to teratogenic agents, prenatal data, type of delivery, birth weight, birth stature, gestational age and results of exams (neonatal screening for metabolic diseases, radiographic evaluations, karyotype, etc.). Samples of peripheral or umbilical cord blood were collected for a karyotype study when indicated in order to confirm or investigate chromosomal abnormalities. Other genetic tests were performed depending on the needs of each individual.

Results were stratified according to BDs and epidemiological parameters. Statistical analysis was performed using the Minitab (version 16) and GraphPad statistical programs. Descriptive statistics using frequencies and proportions were employed to describe the demographic characteristics of subjects. The effects were evaluated by $95 \%$ confidence intervals $(95 \% \mathrm{CIs})$. Statistical analyses included the paired t-test, and Mann-Whitney, chi-square, and Fischer's exact tests, adopting a level of significance of 5\%.

\section{Results}

One hundred and sixty-nine individuals were identified as having BDs revealing an incidence of 3.2\% (95\% CI: $2.8-3.8 \%$ ). Table 1 shows the characteristics of subjects with birth defects.

The gestation age of babies with BDs ranged from 20 to 42 weeks [mean: 36.0 weeks; standard deviation (SD): 3 weeks and 6 days]. With respect to the gestational age,

Table 1 - Characteristics of subjects with birth defects.

\begin{tabular}{lcc}
\hline Factors & Cases (\%) & $95 \% \mathrm{CI}$ \\
\hline Live Births & $158(93.5 \%)$ & $88.7-96.3 \%$ \\
Stillbirths & $11(6.5 \%)$ & $3.7-11.3 \%$ \\
Male & $95(56.2 \%)$ & $48.7-63.5 \%$ \\
Female & $66(39.0 \%)$ & $32.0-46.6 \%$ \\
Undetermined & $8(4.7 \%)$ & $2.4-9.0 \%$ \\
\hline
\end{tabular}

$\mathrm{CI}=$ exact confidence interval.
41.2\% (95\%CI: $34.0-48.8 \%)$ were preterm ( $<37$ weeks) and $58.2 \%$ (95\%CI: $37.2-60.0 \%)$ were born at term $(\geq 37$ weeks). The majority of children $(92.3 \%$; $95 \%$ CI: $85.9-$ $97.2 \%)$ were delivered by $\mathrm{C}$-section and $42.0 \%(95 \% \mathrm{CI}$ : $28.4-49.6 \%)$ had low birth weights $(<2500 \mathrm{~g})$.

For the Control Group, the period of gestation ranged from 33 to 41 weeks (mean: 38 weeks; SD: 1 week and 2 days), $16.6 \%$ (95\%CI: $13.4-31.5 \%$ ) were preterm and $83.4 \%$ (95\% CI: $68.5-86.6 \%)$ were born at term. The majority $(93.0 \%$; 95\%CI: $87.4-98.0 \%)$ were delivered by Csection and $14.7 \%$ (95\%CI: $10.2-20.9 \%)$ had low birth weights $(<2500 \mathrm{~g})$. Differences between the groups were statistically significant in respect to the period of gestation $(p$-value $=0.0)$ and birth weight $(p$-value $=0.0)$. There was no significant difference observed in the frequencies of C-sections ( $p$-value $=0.8$ )

Karyotype alterations were detected in 25 individuals; $0.48 \%$ (95\%CI: $0.33-0.71 \%$ ) of the total sample (5204 individuals) and $14.8 \%$ (95\%CI: $10.2-20.9 \%)$ of the individuals with BDs (169 individuals). The most common finding was chromosome 21 trisomy (16 cases $-64.0 \%$; 95\%CI: $44.5-79.7 \%$ ), followed by chromosome 13 trisomy (5 cases - 20.0\%; 95\%CI: 8.9-39.1\%), chromosome 18 trisomy ( 2 cases $-8.0 \%$; 95\%CI: 2.2-25.0\%), X chromosome monosomy ( 1 case $-4.0 \%$; $95 \%$ CI: $0.7-19.5 \%$ ) and $\operatorname{del}(8)($ pter $\rightarrow$ q24:) ( 1 case $-4.0 \%$; 95\%CI: 0.7-19.5\%).

The frequencies of BDs are listed in Table 2. Isolated heart diseases $(11.2 \%$; $95 \%$ CI: $7.3-16.9 \%)$ were the most common BDs followed by Down syndrome $(9.5 \% ; 95 \%$ CI: $5.9-14.8 \%)$, neural tube defects $(8.9 \%$; $95 \% \mathrm{CI}$ : 5.4$14.1 \%)$, urinary tract anomalies $(7.7 \%$; $95 \% \mathrm{CI}$ : $4.4-$ $12.7 \%)$, and polydactyly $(7.0 \%$; $95 \% \mathrm{CI}: 4.0-12.0 \%)$. According to the classification of Garne et al. (2011), isolated anomalies were more frequent, followed by chromosomal syndromes, monogenic diseases, multiple congenital anomalies, and environmental diseases.

Table 3 lists the frequencies of risk factors that were observed in controls and affected children. The frequencies of family members with the same BD (cleft lip/palate - 4 cases, polydactyly - 2 cases, and abnormality of the 3rd toe bilaterally - 1 case), cases of maternal alcohol consumption, gestational diabetes, and previous miscarriages were statistically different between the two groups. The intake of periconceptional folate by mothers of children with BDs and controls was $21.6 \%$ and $28.4 \%$, respectively, which was not statistically different between the two groups.

The mean maternal age for mothers of babies with BDs was 28.0 years $(95 \%$ CI: $26.9-29.2 \%$; range: $14-45$ years; SD: 7.3 years) and for control mothers was 26.0 years (95\%CI: $25.0-26.9 \%$; range: $14-41$ years; SD: 6.2 years). Of the mothers of babies with BDs, $66.0 \%(95 \%$ CI: $58.6-72.8 \%$ ) were aged from 20 to 34 years, $19.6 \%$ (95\%CI: $14.3-26.3 \%)$ were 35 years old or more, and $14.3 \%(95 \% \mathrm{CI}: 9.8-20.4 \%)$ were under 19 years old. Among the Control Group mothers, $74.0 \%$ (95\%CI: 66.8- 
Table 2 - Test for independent interaction of SNPs with LOAD.

\begin{tabular}{|c|c|c|c|c|c|c|}
\hline Polymorphism & AD Patients N (\%) & Controls N (\%) & OR $(95 \%$ IC) & $p$-value ${ }^{\mathrm{a}}$ & OR $(95 \%$ IC) & $p$-value \\
\hline \multicolumn{7}{|c|}{$A B C A 7(\mathrm{rs} 3764650)$} \\
\hline $\mathrm{T}$ & $52(68.4 \%)$ & $105(75.5 \%)$ & 1 (Reference) & - & 1 (Reference) & - \\
\hline G & $24(31.6 \%)$ & $34(24.5 \%)$ & $\begin{array}{c}1.425 \\
(0.767-2.648)\end{array}$ & 0.262 & $\begin{array}{c}1.552 \\
(0.794-3.037)\end{array}$ & 0.199 \\
\hline \multicolumn{7}{|c|}{$C L U(\operatorname{rs} 11136000)$} \\
\hline $\mathrm{C}$ & $89(57.1 \%)$ & $170(58.6 \%)$ & 1 (Reference) & - & 1 (Reference) & - \\
\hline $\mathrm{T}$ & $67(42.9 \%)$ & $120(41.4 \%)$ & $\begin{array}{c}0.938 \\
(0.632-1.390)\end{array}$ & 0.764 & $\begin{array}{c}0.840 \\
(0.537-1.314)\end{array}$ & 0.445 \\
\hline \multicolumn{7}{|c|}{ BIN1 (rs744373) } \\
\hline $\mathrm{T}$ & $106(67.1 \%)$ & $186(65 \%)$ & 1 (Reference) & - & 1 (Reference) & - \\
\hline $\mathrm{C}$ & $52(32.9 \%)$ & $100(35 \%)$ & $\begin{array}{c}0.912 \\
(0.605-1.377)\end{array}$ & 0.662 & $\begin{array}{c}0.960 \\
(0.606-1.520)\end{array}$ & 0.861 \\
\hline \multicolumn{7}{|c|}{$A P O E(\mathrm{rs} 429358$ rs7412) } \\
\hline$\varepsilon 4-$ & $103(65.2 \%)$ & $245(84.5 \%)$ & 1 (Reference) & - & 1 (Reference) & - \\
\hline$\varepsilon 4+$ & $55(34.8 \%)$ & $45(15.5 \%)$ & $\begin{array}{c}2.907 \\
(1.842-4.588)\end{array}$ & $<0.001$ & $\begin{array}{c}3.029 \\
(1.873-4.898) \\
\end{array}$ & $<0.001$ \\
\hline
\end{tabular}

$\varepsilon 4-=\varepsilon 4$ non-carriers; $\varepsilon 4+=\varepsilon 4$ carriers; AD Patients $=$ Alzheimer's disease patients; OR $=$ odds ratio; $\mathrm{CI}=$ confidential interval; $p$-value considered $\leq$ $0.05 ;{ }^{\mathrm{a}}$ crude $p$-value; ${ }^{\mathrm{b}} p$-value adjusted by the variables age, gender, educational attainment, ethnic background and APOE $\varepsilon 4$ status; ${ }^{\mathrm{c}}=p$-value adjusted by the variables on ${ }^{\mathrm{b}}$ except for APOE $\varepsilon 4$ status.

Table 3 - Characteristics of subjects and their relationship with birth defects.

\begin{tabular}{|c|c|c|c|c|c|}
\hline Factors & Cases N (\%) & Controls N (\%) & $\mathrm{p}$ & OR & $95 \% \mathrm{CI}$ \\
\hline Parental consanguinity & $\mathrm{N}=167$ & $\mathrm{~N}=169$ & & & \\
\hline No & $164(98.2)$ & $169(100)$ & 0.210 & - & $0-2.38$ \\
\hline Yes & $3(1.8)$ & $0(0)$ & & & \\
\hline Family history of the same birth defect & $\mathrm{N}=167$ & $\mathrm{~N}=169$ & & & \\
\hline No & $160(95.8)$ & $169(100)$ & $0.007 *$ & - & $0-0.67$ \\
\hline Yes & $7(4.2)$ & $0(0)$ & & & \\
\hline Maternal alcohol consumption & $\mathrm{N}=165$ & $\mathrm{~N}=169$ & & & \\
\hline No & $144(87.3)$ & $162(95.9)$ & $0.008^{*}$ & 3.37 & $1.39-8.17$ \\
\hline Yes & $21(12.7)$ & $7(4.1)$ & & & \\
\hline Gestational diabetes & $\mathrm{N}=167$ & $\mathrm{~N}=169$ & & & \\
\hline No & $158(94.6)$ & $168(99.4)$ & $0.023^{*}$ & 9.56 & $1.19-76.4$ \\
\hline Yes & $9(5.4)$ & $1(0.6)$ & & & \\
\hline Previous miscarriage & $\mathrm{N}=167 ; \%$ & $\mathrm{~N}=169 ; \%$ & & & \\
\hline No & $132(79.0)$ & $155(91.8)$ & $0.000^{*}$ & 2.93 & $1.51-5.69$ \\
\hline Yes & $35(21.0)$ & $14(8.2)$ & & & \\
\hline Twin pregnancy & $\mathrm{N}=169$ & $\mathrm{~N}=169$ & & & \\
\hline No & $158(93.5)$ & $166(98.2)$ & 0.056 & 3.85 & $1.05-14.0$ \\
\hline Yes & $11(6.5)$ & $3(1.8)$ & & & \\
\hline
\end{tabular}

$\mathrm{OR}=$ odds ratio; $\mathrm{CI}=$ exact confidence interval; *statistically significant.

$80.0 \%)$ were aged from 20 to 34 years, $17.7 \%$ (95\% $\mathrm{CI}$ : $12.7-24.2 \%$ ) were under 19 years old, and $8.3 \%$ (95\% CI: $5.0-13.4 \%$ ) were 35 years old or more. Significantly more mothers of affected children had advanced age $(\geq 35)$ than in Control Group mothers ( $p$-value $=0.008)$. Forty-six percent (95\%CI: $27.9-64.9 \%$ ) of the mothers of children with numerical chromosomal abnormalities were at least 35 years old.

The mean age of the fathers of babies with BDs was 31.5 years old $(95 \% \mathrm{CI}$ : $30.2-32.7 \%$; range: $17-54$ years; SD: 7.9 years) and for the Control Group fathers it was 29.6 years (95\%CI: 28.6-30.6\%; range: $17-49$ years; SD: 6.5 
years) Advanced age $(\geq 40)$ was seen in $15 \%(95 \% \mathrm{CI}$ : 9.8-21.0\%) of the fathers of the BD Group and $6 \%(95 \% \mathrm{CI}$ : $2.8-10.6 \%$ ) of the Control Group ( $\mathrm{p}$-value $=0.016$ ). None of the fathers of children with monogenic syndromes was over 40 years old.

\section{Discussion}

Studies of BDs should address the collection, analysis, and dissemination of information and contribute to local interventions such as prevention, diagnosis, and treatment. However, in many low- and middle-income countries, BDs are not considered a public health priority and are perceived by the medical community as rare, unpreventable events. There are few studies performed in these countries and most are usually hospital-based (Groisman et al., 2013). In Brazil, the situation is not different, and this population-based study can be considered an example of the BDs reality in a country that has a highly mixed population with broad cultural diversity (IBGE, 2016).

Although the incidence of BDs around the world is variable, most studies report 3-5\% in different populations (Oliveira et al., 2011). The incidence in this study (3.2\%) corroborates previously described data despite the differences in diagnostic levels, sample sizes, and methodologies of other studies performed both in Brazil (1.4-5\%) and other countries (Oliveira et al., 2011; Gill et al., 2012; Naim et al., 2013). The incidence of BDs was slightly higher in males than in females as has previously been reported(Asindi et al., 1997).

Many infants with BDs have low birth weights and are premature. Globally, an estimated 13 million babies are born annually before completing 37 weeks of gestation with the rates generally being the highest in low- and middle-income countries. Even so, preterm birth rates vary greatly within countries and are related to sociodemographic characteristics (Lawn et al., 2010). In the current study population, the frequency of premature births and babies weighing less than $2500 \mathrm{~g}$ was high compared to the world literature (Lawn et al., 2010; Herbert et al., 2012). Ordinarily, much higher incidences of congenital anomalies are observed among children who weigh $2500 \mathrm{~g}$ or less at birth than among those who are heavier (Herbert et al., 2012).

Generally, the rate of $\mathrm{C}$-sections is related to prematurity and low weight as they are performed for convenience reasons. Elective preterm $\mathrm{C}$-sections are still largely practiced in cases of prenatal diagnoses of major congenital anomalies (Calisti et al., 2012). The C-section was the commonest mode of delivery in both the BD and Control Groups. This was expected because it is common for parents to opt for this kind of delivery in Brazil, regardless of the fetal status (Freitas et al., 2015).

Most chromosomal defects are lethal and identified after miscarriages. They account for a high rate of congeni- tal anomalies. For example, trisomies of chromosomes 13, 18 , and 21 and $\mathrm{X}$ chromosome monosomy have an impact on births ( $\sim 0.3 \%$ of all births; Wiener-Megnazi et al., 2012), and their frequency was similar in the current study. However, the trisomy of chromosome 21 (the second most common BD observed here) affects approximately 1 in 660 births (Hwang and Jea, 2013) with the incidence in the current study being 2 in 660, twice as high as generally described. This could be explained by the significant advanced age observed among mothers; it should also be considered that abortion is illegal in Brazil.

Congenital heart diseases are the most common BDs in humans. They can be isolated or one of multiple defects (Weber, 2012; Zaidi et al., 2013). In this study, heart diseases in isolation were the most common BD. The frequency of neural tube defects ranges from 0.2 to 10 per 1000 live births in specific geographical locations (Copp et al., 2013). In this study, this was the third most common BD. Other BDs, such as congenital anomalies of the kidneys and urinary tract, and polydactyly, the fourth and fifth most common findings, respectively, are among the most common anomalies in newborn infants (Richter-Rodier et al.; 2012; Liu et al., 2016).

The incidence of BDs not only reflects allelic frequencies of deleterious genes in a population but it is also affected by environmental factors (Alaani et al., 2011; Naim et al., 2012). Of the known risk factors for congenital abnormalities that were investigated in this study, the frequencies of familial recurrence, maternal alcohol consumption, gestational diabetes, previous miscarriages and advanced maternal age were significantly higher in the BD Group than the Control Group.

Similar to previous descriptions, certain BDs in this study recurred in families, such as non-syndromic oral cleft, polydactyly and abnormalities in the position of fingers (Jones, 2007; Grosen et al., 2010; Ravichandran et al., 2012).

Three times more mothers of the BD Group consumed alcohol during pregnancy. In Brazil, as in other countries, this is a health problem (Feldmanet al., 2012; Veloso and Souza Monteiro, 2013). In the United States, approximately 80,000 women annually consume alcoholic beverages through all three trimesters of pregnancy. Prenatal alcohol exposure is a risk factor for BDs and can lead to a wide range of adverse effects in a developing fetus. Fetal alcohol spectrum disorder is a developmental disorder that affects up to $0.2 \%$ of births(Bates, 2013). The risk of comorbid disorders is also increased for this population; this increases the phenotype severity and complexity of management (Paintner et al., 2012; Viteri et al., 2015).

The rate of gestational diabetes mellitus was significantly different between the groups. This is believed to be a risk factor as it has been correlated to limb and heart defects, as observed in this study. Epidemiologic studies have 
shown that low glycemic dietary management can reduce the incidence of BDs (Reece, 2012; Glover et al., 2016).

Recurrent pregnancy loss affects $2-5 \%$ of all couples with $>50 \%$ being characterized as unexplained or idiopathic (Hodes-Wertz et al., 2012). The results of this study showed that the rate of previous miscarriages in mothers of the BD Group was significantly higher. Indeed, previous miscarriages are considered to be a risk factor for future babies to have some type of $\mathrm{BD}(\mathrm{Lu}$ et al., 2011; Machado et al., 2013).

More women are delaying child bearing, which results in an annual rate of $14.9 \%$ of live births to women aged 35 years or older (Hamiltonet al., 2010). Both younger and older maternal ages may pose increased risks for BDs (Miller et al., 2011; Gill et al., 2012). In this study, about $20 \%$ of mothers of babies with BDs were at least 35 years old. Thus, the effect of advanced maternal age was, as expected, greatly related to BDs, such as Down syndrome. Although advanced paternal age has been associated with an increased risk for congenital disorders (Kong et al., 2012; Wiener-Megnazi et al., 2012; Goriely and Wilkie, 2012), this was not observed in the current study.

There was no significant difference between the BD and Control Groups in relation to the rate of consanguineous marriages and twin pregnancies, considered major risk factors for congenital anomalies (Weller et al., 2012; Boyle et al., 2013; Sheridan et al., 2013; Maghsoudlou et al., 2015); however, one case of Smith-Lemli-Opitz syndrome, an autosomal recessive disorder (Quélin et al., 2012), probably resulted from parental consanguinity.

Neural tube defects were one of the most common BDs observed in this study, as is reported in publications around the world, with a prevalence from 1-10\% (Wang et al., 2013). A prudent periconception supplementation with folic acid may decrease the risk, as well as the threat of heart defects and other BDs (Czeizel, 2012; Sotres-Alvarez et al., 2013). In this study, the periconception supplementation did not differ between the groups and was low, below the expected, for a developed region.

Infant mortality is one of the most important conditions to be considered in relation to BDs because it is indicative of the health of a community or country. Early recognition of anomalies is important for planning and care (Calisti et al. (2012). For example, congenital disorders continue to be a leading cause of infant mortality and rank within the top 15 contributors to the global burden of disease, even though many congenital disorders are preventable (Shannon et al., 2013). Thus, the identification of incidence, risk factors, and consequences of BDs are essential to plan preventive measures and effective treatment.

Findings involving BDs around the world vary due to the methods of investigation and differ because of the cultural, social, and geographic context of each population. No similar study for Brazil was found, i.e., involving birth data of all infants born in a municipality over a period of time.
The studies on BDs are usually performed with a hospital-based sample of births. Even the Latin-American collaborative study of congenital malformations (ECLAMC), a program for the clinical and epidemiological investigation of risk factors in the etiology of congenital anomalies in Latin-American hospitals (Castilla and Orioli, 2004), offers limited information, since the number of participant hospitals is still small (Guerra et al., 2008).

Based on these preliminary findings, this population-based study performed in Brazil can collaborate in developing strategies for the healthcare and education needs of the population. The incidence of BDs reported was similar to published data from other countries, but the incidence of Down syndrome was twice as high as the rate reported in the literature. This can be the result of the reality in the region where the study was performed. The region is economically more advanced and many women delay child bearing, increasing the risk for congenital abnormalities. Family history of the same BDs, maternal alcohol consumption, gestational diabetes, and previous miscarriages were the more frequent risk factors. In this context, different strategies should be developed to reduce the occurrence of BDs depending on the current situation of congenital defects in different regions.

\section{Acknowledgments}

The authors wish to thank the expert evaluators and the parents for their collaboration in this study.

\section{Conflict of interest}

The authors declare no conflict of interest.

\section{Author contributions}

CIFO-B carried out the data collection, karyotypic analysis and confection of the manuscript. VCCF carried out the karyotypic analysis. ARC participated in the investigation of the diagnoses. ACF-C designed the study, clinical assessment, oversaw the whole study and did the critically reviewing manuscript. All authors read, revised and approved the final manuscript.

\section{References}

Alaani S, Savabieasfahani M, Tafash M and Manduca P (2011) Four polygamous families with congenital birth defects from Fallujah, Iraq. Int $\mathrm{J}$ Environ Res Public Health 8: 89-96.

Arioglu Aydin Ç, Aydin S and Serdaroglu H (2016) Multifetal gestations with assisted reproductive technique before the single-embryo transfer legislation: obstetric, neonatal outcomes and congenital anomalies. J Matern Fetal Neonatal Med 29:2475-2480.

Asindi AA, Al Hifzi I and Bassuni WA (1997) Major congenital malformations among Saudi infants admitted to Asir Central Hospital. Ann Saudi Med 17:250-253. 
Bates EA (2013) A potential molecular target for morphological defects of fetal alcohol syndrome: Kir2.1. Curr Opin Genet Dev 23:324-329.

Boyle B, McConkey R, Garne E, Loane M, Addor MC, Bakker MK, Boyd PA, Gatt M, Greenlees R, Haeusler M et al. (2013) Trends in the prevalence, risk and pregnancy outcome of multiple births with congenital anomaly: A registry-based study in 14 European countries 1984-2007. BJOG 120:707-716.

Calisti A, Oriolo L, Giannino G, Spagnol L, Molle P, Buffone EL and Donadio C (2012) Delivery in a tertiary Center with co-located surgical facilities makes the difference among neonates with prenatally diagnosed major abnormalities. J Matern Fetal Neonatal Med 25: 1735-1737.

Castilla EE and Orioli IM (2004) ECLAMC: the Latin-American collaborative study of congenital malformations. Community Genet 7:76-94.

Copp AJ, Stanier P and Greene ND (2013) Neural tube defects: recent advances, unsolved questions, and controversies. Lancet Neurol 12: 799-810.

Czeizel AE (2012) Experience of the Hungarian Preconception Service between 1984 and 2010. Eur J Obstet Gynecol Reprod Biol 161:18-25.

Feldman HS, Jones KL, Lindsay S, Slymen D, Klonoff-Cohen H, Kao K, Rao S and Chambers C (2012) Prenatal alcohol exposure patterns and alcohol-related birth defects and growth deficiencies: a prospective study. Alcohol Clin Exp Res 36:670-676.

Freitas PF, Drachler ML, Leite JC and Grassi PR (2005) Social inequalities in cesarean section rates in primiparae, Southern Brazil. Rev Saude Publ 39:761-767.

Garne E, Dolk H, Loane M, Wellesley D, Barisic I, Calzolari E, Densem J and EUROCAT Working Group (2011) Surveillance of multiple congenital anomalies: implementation of a computer algorithm in European registers for classification of cases. Birth Defects Res A Clin Mol Teratol 91:44-50.

Gill SK, Broussard C, Devine O, Green RF, Rasmussen SA, Reefhuis J and National Birth Defects Prevention Study (2012) Association between maternal age and birth defects of unknown etiology - United States, 1997-2007. Birth Defects Res A Clin Mol Teratol 94:1010-1018.

Glover AV, Tita A, Biggio JR and Harper LM (2016) Examining the starting dose of glyburide in gestational diabetes. Am J Perinatol. 33:214-220.

Goriely A and Wilkie AO (2012) Paternal age effect mutations and selfish spermatogonial selection: Causes and consequences for human disease. Am J Hum Genet 90:175-200.

Groisman B, Bidondo MP, Gili JA, Barbero P and Liascovich R (2013) Strategies to achieve sustainability and quality in birth defects registries: the experience of the national registry of congenital anomalies of Argentina. J Registry Manag 40:29-31.

Grosen D, Chevrier C, Skytthe A, Bille C, Mørtensen K, Sivertsen A, Murray JC and Christensen K (2010) A cohort study of recurrence patterns among more than 54,000 relatives of oral cleft cases in Denmark: support for the multifactorial threshold model of inheritance. J Med Genet 47:162-168.

Guerra FA, Llerena Jr JC, Gama SG, Cunha CB and Theme Filha MM (2008) Reliability of birth defect data on birth certificates of Rio de Janeiro, Brazil, 2004. Cad Saude Publ 24:438-446.
Hamilton BE, Martin JA, Ventura SJ and Division of Vital Statistics (2010) Births: Preliminary Data for 2009. Natl Vital Statist Rep 59:1-19.

Herbert DL, Lucke JC and Dobson AJ (2012) Birth outcomes after spontaneous or assisted conception among infertile Australian women aged 28 to 36 years: A prospective, population-based study. Fertil Steril 97:630-638.

Hodes-Wertz B, Grifo J, Ghadir S, Kaplan B, Laskin CA, Glassner M and Munné S (2012) Idiopathic recurrent miscarriage is caused mostly by aneuploid embryos. Fertil Steril 98:675-680

Hwang SW and Jea A (2013) A review of the neurological and neurosurgical implications of Down syndrome in children. Clin Pediatr (Phila) 52:845-856.

Jones KLJ (2007) Padrões reconhecíveis de malformações congênitas. 6th edition. Elsevier, Rio de Janeiro, 952 pp.

Kong A, Frigge ML, Masson G, Besenbacher S, Sulem P, Magnusson G, Gudjonsson SA, Sigurdsson A, Jonasdottir A, Wong WS et al. (2012) Rate of de novo mutations and the importance of father's age to disease risk. Nature 488:471475.

Lawn JE, Gravett MG, Nunes TM, Rubens CE, Stanton C and GAPPS Review Group (2010) Global report on preterm birth and stillbirth (1 of 7): Definitions, description of the burden and opportunities to improve data. BMC Pregnancy Childbirth 10:S1.

Liu QG, Sun J, Xiao XW and Song GR (2016) Birth defects data from surveillance hospitals in Dalian City, China, 20062010. J Matern Fetal Neonatal Med 15:1-22.

Lu QB, Wang ZP, Gao LJ, Gong R, Sun XH and Zhao ZT (2011) Previous abortion and the risk of neural tube defects: a case-control study. J Reprod Med 56:431-436.

Machado CJ, Lobato AC, Melo VH and Guimarães MD (2013) Spontaneous and voluntary fetal losses in Brazil in 19992000: A study of associated factors. Rev Bras Epidemiol 16:18-29.

Maghsoudlou S, Cnattingius S, Aarabi M, Montgomery SM, Semnani S, Stephansson O, Wikström AK and Bahmanyar S (2015) Consanguineous marriage, prepregnancy maternal characteristics and stillbirth risk: A population-based casecontrol study. Acta Obstet Gynecol Scand 94:1095-1101.

Miller A, Riehle-Colarusso T, Siffel C, Frías JL and Correa A (2011) Maternal age and prevalence of isolated congenital heart defects in an urban area of the United States. Am J Med Genet A 155A:2137-2145.

Naim A, Al Dalie H, El Balawi M, Salem E, Meziny K, Sharwwa R, Minutolo R and Manduca P (2012) Birth defects in Gaza: Prevalence, types, familiarity and correlation with environmental factors. Int J Environ Res Public Health 9:17321747.

Oliveira CIF, Richieri-Costa A, Carvalho Ferrarese VC, Móz Vaz DC and Fett-Conte AC (2011) Birth defects in newborns and stillborns: an example of the Brazilian reality. BMC Res Notes 9:343.

O’Neill SM, Kearney PM, Kenny LC, Khasan AS, Henriksen TB, Lutomski JE and Greene RA (2013) Caesarean delivery and subsequent stillbirth or miscarriage: systematic review and meta-analysis. PLoS One 8:e54588.

Ooki S (2013) Maternal age and birth defects after the use of assisted reproductive technology in Japan, 2004-2010. Int J Womens Health 5:65-77. 
Paintner A, Williams AD and Burd L (2012) Fetal alcohol spectrum disorders - implications for child neurology, part 2: diagnosis and management. J Child Neurol 27:355-362.

Quélin C, Loget P, Verloes A, Bazin A, Bessiéres B, Laquerrière A, Patriere R, Grigorescu R, Encha Razavi F, Delahaye S et al. (2012) Phenotypic spectrum of fetal Smith-Lemli-Opitz syndrome. Eur J Med Genet 55:81-90.

Ravichandran K, Shoukri M, Aljohar A, Shazia NS, Al-Twaijri Y and Al Jarba I (2012) Consanguinity and occurrence of cleft lip/palate: A hospital-based registry study in Riyadh. Am J Med Genet A 158A:541-546.

Reece EA (2012) Diabetes-induced birth defects: What do we know? What can we do? Curr Diab Rep 12:24-32.

Richter-Rodier M, Lange AE, Hinken B, Hofmann M, Stenger RD, Hoffmann W, Fusch C and Haas JP (2012) Ultrasound screening strategies for the diagnosis of congenital anomalies of the kidney and urinary tract. Ultraschall Med 33:333338.

Shannon GD, Alberg C, Nacul L and Pashayan N (2013) Preconception health care and congenital disorders: mathematical modelling of the impact of a preconception care programme on congenital disorders. BJOG 120:555-566.

Sheridan E, Wright J, Small N, Corry PC, Oddie S, Whibley C, Petherick ES, Malik T, Pawson N, McKinney PA et al. (2013) Risk factors for congenital anomaly in a multiethnic birth cohort: an analysis of the Born in Bradford study. Lancet 382:1350-1359.

Sotres-Alvarez D, Siega-Riz AM, Herring AH, Carmichael SL, Feldkamp ML, Hobbs CA, Olshan AF and National Birth Defects Preventiomn Study (2013) Maternal dietary patterns are associated with risk of neural tube and congenital heart defects. Am J Epidemiol 177:1279-1288.

Veloso LU and de Souza Monteiro CF (2013) Prevalence and factors associated with alcohol use among pregnant adolescents. Rev Lat Am Enfermagem 21:433-441.
Viteri OA, Soto EE, Bahado-Singh RO, Christensen CW, Chauhan SP and Sibai BM (2015) Fetal anomalies and long-term effects associated with substance abuse in pregnancy: a literature review. Am J Perinatol 32:405-416.

Wang M, Wang ZP, Gao LJ, Gong R, Sun XH and Zhao ZT (2013) Maternal body mass index and the association between folic acid supplements and neural tube defects. Acta Paediatr 102:908-913.

Weber S (2012) Novel genetic aspects of congenital anomalies of kidney and urinary tract. Curr Opin Pediatr 24:212-218.

Weller M, Tanieri M, Pereira JC, Almeida Edos S, Kok F and Santos S (2012) Consanguineous unions and the burden of disability: A population-based study in communities of Northeastern Brazil. Am J Hum Bio 24:835-840.

Wiener-Megnazi Z, Auslender R and Dirnfeld M (2012) Advanced paternal age and reproductive outcome. Asian $\mathrm{J}$ Androl 14:69-76.

Zaidi S, Choi M, Wakimoto H, Ma L, Jiang J, Overton JD, Romano-Adesman A, Bjornson RD, Breitbart RE, Brown KK et al. (2013) De novo mutations in histone-modifying genes in congenital heart disease. Nature 498:220-223.

\section{Internet Resources}

IBGE (2016) Instituto Brasileiro de Geografia e Estatística. Indicadores, http://www.ibge.gov.br/home. (accessed 26 June 2016).

Associate Editor: Mara H.Hutz

License information: This is an open-access article distributed under the terms of the Creative Commons Attribution License (type CC-BY), which permits unrestricted use, distribution and reproduction in any medium, provided the original article is properly cited. 